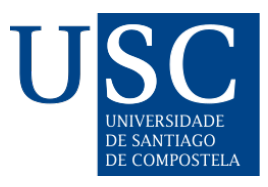

\title{
Seguridad y libertad en el sistema democrático: Actas del XVII Congreso de la Asociación de Constitucionalistas de España
}

\author{
Rubén Miranda Gonçalves ${ }^{1}$ \\ Universidad Internacional de La Rioja, España
}

La obra objeto de recensión, fruto de la coordinación del profesor José Julio Fernández Rodríguez, nace a raíz del XVII Congreso de la Asociación de Constitucionalistas de España que se realizó los días 4 y 5 de abril de 2019 en la Universidad de Santiago de Compostela y que llevó por título "Seguridad y libertad en el sistema democrático".

En esta monografía el lector tendrá acceso al contenido de las diferentes intervenciones que realizaron los ponentes del congreso, todos ellos brillantes expertos en derecho constitucional y juristas de reconocido prestigio académico: Roberto Blanco Valdés, Miguel Revenga Sánchez, Arianna Vedaschi, Bartolomé Bauzá Abril, Pablo Lucas Murillo de la Cueva, Rosario Serra Cristóbal, Jorge Lozano Miralles, José Julio Fernández Rodríguez, Susana Sánchez Ferro, Ana Aba Catoira, Mónica Arenas Ramiro, Cristina Pauner Chulvi, Joan Lluís Pérez Francesch, Aida Torres Pérez, Cian C. Murphy y Christie S. Warren.

La primera parte se inicia con el diálogo ¿Qué libertad y qué seguridad queremos? ¿Y cuál necesitamos?, en el que intervienen Miguel Revenga, Arianna Vedaschi y Bartolomé Bauzá. La presentación y moderación del mismo corre a cargo del Catedrático de Derecho Constitucional de la Universidad de Santiago de Compostela, Roberto Blanco Valdés, quién aprovecha para recordar la figura del Estado constitucional y su vinculación con la idea moderna de seguridad y libertad, principios esenciales que debe garantizar todo Estado constitucional.

Miguel Revenga Sánchez, Catedrático de Derecho Constitucional de la Universidad de Cádiz, titula su intervención “¿Qué derecho a la libertad y a la seguridad queremos?”. Para el profesor Revenga se trata de un dilema complicado, pues valorar la libertad o evaluar la seguridad es algo esencial para conocer hasta qué punto las personas están dispuestas a ceder espacios propios en beneficio de otros, siendo que unos optarán por priorizar la seguridad y otros apostarán por la libertad. En este sentido, Miguel Revenga opta por una seguridad que no podrá ser coartada para estigmatizaciones abstractas que persigan a las personas por razón de su pertenencia ética o por sus creencias religiosas; que esa seguridad racionalice y que sea compatible con la libertad y el respeto de los derechos.

En términos similares, la aportación de la doctora Arianna Vedaschi estudia la relación entre la necesidad y la demanda de seguridad y libertad y como ambos conceptos tienen tres dimensiones: la dimensión querida por las personas, la que necesitan y la percibida. Vedaschi opta por afirmar que los legisladores deben contextualizar estas percepciones en un marco de mayor complejidad para no "sofocar" o restringir la libertad, elemento vital de todo Estado constitucional. Pero ¿qué 
tipo de derecho es el derecho a la seguridad? Ante esta pregunta, la profesora Vedaschi señala varias teorías en las que se sostiene que puede ser un derecho personal, también un derecho social y, en tercer lugar, un valor supremo.

La autora culmina su intervención con dos ejemplos prácticos. En primer lugar, "las relaciones entre la seguridad y la inmigración en el marco normativo italiano", una clara muestra de cómo las exigencias de la seguridad nacional impulsan a los legisladores y a los gobiernos a endurecer la lucha contra el terrorismo, cuyo fin último es la reducción de los flujos migratorios, pues se considera al migrante como una amenaza a la seguridad y, por último, "un nuevo balance y la "extraterritorialidad" de los derechos en el Dictamen 1/15 del Tribunal de Justicia de la Unión Europea", en el que se calibran las relaciones entre libertad y seguridad y el alto tribunal rechaza colocar a la seguridad en la cúspide jerárquica y la combina con la libertad, a fin de que ambas puedan coexistir al mismo nivel.

Para finalizar este diálogo, el contraalmirante Bartolomé Bauzá Abril hace un examen de la seguridad desde el punto de vista geoestratégico y afirma que la libertad necesita de la seguridad, pues son conceptos íntimamente ligados. Además, hace referencia a la "responsabilidad de proteger", a través de la cual la comunidad internacional intervenía en asuntos internos de países cuando detectaba violaciones de derechos humanos, por ejemplo, como fue el caso de los antiguos territorios de Yugoslavia o, más recientemente, en Libia.

La segunda parte de la obra está compuesta por las intervenciones de los profesores Pablo Lucas Murillo de la Cueva, quien presenta y modera, Rosario Serra Cristóbal y Jorge Lozano Miralles titulada "El desafío Constitucional del Terrorismo". En ella se plantea la forma en la que los ordenamientos constitucionales han afrontado el terrorismo y como el ordenamiento jurídico español hizo mención en el año 1978 a los grupos terroristas, hecho que suscitó cierta preocupación al no ser una cuestión común en las constituciones de la época. En todo caso, afirma Murillo de la Cueva que, a pesar del sufrimiento causado por los distintos terrorismos que asolaron España, no lograron su cometido, que era el de desestabilizar la convivencia democrática y quebrar las instituciones constitucionales.

Rosario Serra Cristóbal, catedrática de Derecho Constitucional en la Universidad de Valencia, analiza el desafío constitucional del terrorismo y sostiene que el Estado tiene como funciones principales proteger la igualdad, la justicia y la seguridad, siempre para garantizar la libertad de sus ciudadanos, aunque para conseguirlo suponga riesgos, especialmente con fenómenos como el terrorismo yihadista. Tanto la libertad como la seguridad son dos de los elementos por los que más ha luchado el hombre desde sus orígenes, por lo que no pueden ser mermados en ningún caso.

En una situación como la actual, en la que el fuerte avance de la tecnología ha facilitado el incremento de los ataques terroristas, el Estado deberá perseguir a los delincuentes y, a mayores, evitar que se perpetren nuevos ataques, pues los derechos fundamentales están en juego. No obstante, no debemos olvidarnos, sostiene la autora, que luchar contra el terrorismo y, especialmente, en la era digital, no depende únicamente del Estado en sentido singular, pues es necesaria la cooperación entre países.

En esa dirección, Jorge Lozano Miralles, catedrático de Derecho Constitucional en la Universidad de Jaén, examina la seguridad como premisa de la lucha contra el terrorismo, pues ambos conceptos pueden ser estudiados desde su conjunto. Para el profesor Lozano la seguridad no es un problema nuevo y, además, la idea de seguridad tampoco es igual en todos los ámbitos y contextos, pues los tipos de amenazas van variando de comunidad en comunidad, de Estado en Estado, región en región etc. Lo que sí es nuevo, apunta el autor, es el concepto de seguridad nacional, entendido como las 
medidas que tienden a proteger la existencia de la nacional, su propia integridad territorial o su independencia política contra la fuerza o la amenaza de la fuerza.

Este nuevo concepto de seguridad, además de proteger a las personas, los bienes y su territorio, tiene aparejados nuevos objetivos como, por ejemplo, la defensa de los principios y valores constitucionales y el sistema de derechos fundamentales, algo que no siempre es fácil de lograr.

La segunda mesa de debate lleva por título "Actividad de Inteligencia” y compone la tercera parte de la obra. La moderación y presentación corre a cargo del profesor José Julio Fernández Rodríguez, quien afirma que la importancia de la inteligencia ha crecido de forma paralela a la propia dinámica de las amenazas, riesgos y desafíos de la seguridad en los últimos años, incrementando la complejidad geoestratégica de los problemas que vienen presionando a la sociedad desde finales de la Guerra Fría. La solución al problema pasa por incrementar la colaboración y cooperación en inteligencia y construir una diligencia más dinámica e integral.

En esta segunda mesa intervienen las profesoras Susana Sánchez Ferro, de la Universidad Autónoma de Madrid y la profesora Ana Aba Catoira, de la Universidad de A Coruña. Ambas analizarán aspectos relacionados con el CNI español. La primera, abordando la estructura, funciones, afectación a la vida privada e intervención de comunicaciones y, la segunda, estudiando la rendición de cuentas de los servicios de inteligencia. Finalmente, se propondrán mejoras concretas a la regulación normativa del CNI y la clasificación de materias reservadas y del propio control en España.

Resulta interesante, desde el punto de vista del derecho comparado, que el CNI español tiene funciones de seguridad interior y también exterior concentradas en el mismo organismo y que no responden solamente a funciones en el campo de la defensa, pues también tienen encomendadas funciones contra terrorismo, terrorismo internacional, espionaje exterior, entre otras, todas ellas para prevenir, detectar y posibilitar la neutralización de actividades de servicios extranjeros, grupos o personas que puedan poner en riesgo, amenazar o atentar contra los derechos y libertades de los ciudadanos españoles.

En el caso español, la profesora Aba Catoira apunta que, aun siendo una cuestión difícil por la exigencia de reserva o secreto de la información, el CNI se encuentra sometido a los controles democráticos para supervisión y revisión de su actividad. En este sentido, se encuentra sometido al control político del poder ejecutivo, al control parlamentario y al control judicial, pero ello no es óbice para que se pueda mejorar la legislación actual para incluir propuestas de mejora, por ejemplo, la mejora de la efectividad del control parlamentario.

La cuarta parte de la obra, titulada "Perspectiva constitucional de los avances tecnológicos en seguridad”, es presentada por Mónica Arenas Ramiro, de la Universidad de Alcalá. En ella se encara el cambio de paradigma y los peligros que han provocado en nuestro sistema democrático la aplicación de las nuevas tecnologías en el terreno de la seguridad nacional. En esta tercera mesa redonda participaron los profesores Cristina Pauner Chulvi y Joan Lluís Pérez Francesch, de la Universidad Autónoma de Barcelona.

En el caso de la profesora Pauner Chulvi hace un estudio de la perspectiva constitucional de los avances tecnológicos en seguridad y su impacto en los derechos fundamentales, en tanto en cuanto la inseguridad es una característica de nuestra sociedad. En su investigación se analizará el concepto de seguridad en relación con las nuevas tecnologías de la información y la comunicación hasta desembocar en un nuevo término que es la ciberseguridad y como esta afecta tanto a las infraestructuras informáticas como también a la información digital. A este respecto, el nuevo escenario para la realización de actividades ilícitas pasa a ser el ciberespacio, objeto de ataques a 
la reputación, influencia, robo de información y ciberataques variados, los cuales ponen en jaque varios derechos fundamentales, especialmente, la protección de los datos de carácter personal.

Pero ¿cuáles son las perspectivas constitucionales de las nuevas tecnologías en seguridad? De esta cuestión se encargará el profesor Pérez Francesch, quien afirma que para luchar contra la inseguridad no todo es válido, pues la libertad política es una garantía de todo Estado democrático y de Derecho como estructura civilizatoria, aunque no sea sencillo encontrar un equilibrio entre seguridad y libertad. La inteligencia artificial, incluso la robótica, pueden llevarnos a una tiranía de la tecnología, sostiene el profesor Pérez Francesch, por tanto, los países deben estar preparados para una nueva cultura de seguridad nacional, algo que todavía no tiene España, siendo necesario para hacer frente a los graves ataques y amenazas globales que puedan afectar al país.

Por último, la obra que el lector tiene en sus manos culmina con las aportaciones de expertos a la cuarta mesa redonda titulada "Liberty and security in contemporary democracies" conducida por la profesora Aida Torres Pérez y cuyos ponentes fueron los profesores Cian C. Murphy y de la profesora Christie S. Warren. En sus intervenciones se han tratado cuestiones tan relevantes como los retos que la legislación antiterrorista plantea para el frágil equilibro que existe entre la libertad y la seguridad en Europa y Estados Unidos.

El profesor Murphy planteó una serie de críticas hacia la ley de la Unión Europea contra el terrorismo, especialmente a raíz de los ataques del 11 de septiembre de 2001, habida cuenta que hubo que responder a un insuficiente derecho y justicia penales a nivel europeo. A partir de ahí, la dimensión institucional de la lucha contra el terrorismo de la Unión Europea incluyó las funciones legislativas y ejecutivas del Parlamento, el Consejo y la Comisión y han sido decisivas para la aplicación de una serie de medidas restrictivas.

No obstante, no ha sido suficiente, pues la ley antiterrorista de la Unión Europea depende de la transposición a la legislación de los Estados miembros para que pueda aplicarse. Ello ha ocasionado que, en muchas ocasiones, las legislaciones de los Estados miembros han sido incapaces de transponer con precisión las medidas de la Unión Europea, desembocando en tres amplias críticas: ineficaz, anticonstitucional y contraria a los derechos humanos y el Estado de derecho.

Por último, concluye la profesora Christie S. Warren con un breve resumen de la lucha contra el terrorismo en la legislación federal y estatal de los Estados Unidos, que puede resultar muy útil para compararlo con otros ordenamientos jurídicos. En el sistema americano, los Estados tienen jurisdicción para legislar en las áreas relacionadas con la seguridad y bienestar público. La jurisdicción federal se extiende a cuestiones que afecten a la seguridad nacional, asuntos exteriores y defensa de la nación.

Por nuestra parte, concluimos esta recensión haciendo un homenaje al coordinador y demás autores por la claridad de sus ideas y por el reto de sintetizar cuestiones tan esenciales como la seguridad y libertad en el sistema democrático. Se trata de una obra no muy extensa pero que sintetiza los aspectos más relevantes, pues no siempre es fácil lograrlo, pero en este caso los autores lo han conseguido. 


\section{Información Adicional:}

Título: Seguridad y libertad en el sistema democrático: Actas del XVII Congreso de la Asociación de Constitucionalistas de España

Autor: José Julio Fernández Rodríguez (Coord.)

Editorial: Tirant lo Blanch

Año de edición: 2020

Páginas: 336

ISBN Papel: 9788413550602

ISBN Ebook: 9788413550619

NOTAS

1 Profesor Contratado Doctor y Director académico del Máster Universitario en Derechos Humanos: Sistemas de Protección en la Universidad Internacional de La Rioja; Doctor en Derecho por la Universidad de Santiago de Compostela; profesor en el Máster en Seguridad, Paz y Conflictos Internacionales de la Universidad de Santiago de Compostela, profesor en la Universidad de La Laguna y profesor 'venia docendi' en la Universidad de Las Palmas de Gran Canaria. 